\title{
Ask a Lawyer
}

\section{Childbirth Educators' Legal and Ethical Responsibilities to Women in Labor}

\author{
Nayna Campbell Philipsen, RN, PhD, JD, LCCE, FACCE
}

NAYNA PHILIPSEN is an attorney in Baltimore, Maryland, associated with the State of Maryland's Department of Health and Mental Hygiene. She is also a health educator at St. Agnes Hospital in Baltimore and a clinical faculty member at the Salisbury State University Department of Nursing.

\begin{abstract}
In answer to a reader's question, the author of this column addresses the legal and ethical responsibilities of a Lamaze Certified Childbirth Educator who agrees to attend her students' drug-free delivery.

Journal of Perinatal Education, 9(1), 49-50; childbirth educators, Lamaze certification, natural childbirth, legal responsibility, ethical responsibility.
\end{abstract}

Question: I am a Lamaze Certified Childbirth Educator (LCCE) and often find myself in the Labor-Delivery Room (LDR) with many of my students. Most request my presence since they wish a drug-free delivery: birth plans clearly indicate no pain medication. What is my legal responsibility to these women in labor when they request drugs?

-A California LCCE

Answer: The short answer is, you respect their autonomy and let them make that decision.

This question has both legal and ethical aspects. Medical ethics used to be "First, do no harm. Second, do all the good you can." The principle expressed in these two statements is called beneficence. That is, you must do what is best for the patient.

Autonomy is the second principle. Who decides "what is best" for the patient? In 1990, the U.S. Congress passed the Patient Self-Determination Act as an amendment to Title XVIII of the Social Security Act, and it became effective December 1, 1991. It put into law a change that has been evolving in all areas of patient care. Restated, medical ethics since 1991 arguably could be, "First, do what the patient wants. Second, do no harm. Third, do all the good you can." As long as the patient is competent, 
. . medical ethics since 1991 arguably could be,

"First, do what the patient wants. Second, do no harm.

Third, do all the good you can."

she has the right to make decisions about her health. She can even refuse options that seem to the caregiver to be in the patient's best interest. Decision-making is ongoing; a patient can change her mind!

Beneficence and autonomy can conflict, especially in obstetrics, where a caregiver has two patients at once. When these two principles conflict, a dilemma may be created. The caregiver's main responsibility is to assure that the patient is informed about all of her options. Lamaze International was an early pioneer for patient autonomy in the United States. Through its promotion of education, advocacy, and reform, Lamaze International enabled women to become active participants in giving birth and to make their own best decisions.

Lamaze International was an early pioneer for patient autonomy in the United States.

As an LCCE, your first priority is to ensure that birthing women are well informed. A woman who fits into your scenario seems capable of making good decisions. She made the decision to attend your classes. She made the decision that her goal is a "drug-free delivery" and she made the decision that your presence would be supportive of that goal. She also will make the decisions about other options as she goes through labor. Of paramount importance is respecting her ability to make these decisions.

If a woman is incompetent for any reason, an independent third party will determine who "stands in her shoes" for medical decision-making, if she has not already determined this through a Power of Attorney for Health Care. Often the state law selects the closest relative, such as a spouse or parent. It is not the childbirth educator or the doctor.

As an LCCE, one of your goals is to help an expectant mother recognize in advance that each birth is unique. When you agree to be present to help her make this one-of-a-kind, exciting, and sometimes very challenging journey, she is the driver. Let her know that you will support her to the end of the race, regardless of unexpected turns in the road and regardless of how she runs. With your confidence, she will do her best. Your duty is to follow her lead.

Let's return to your scenario. You have a student who requests your presence in the LDR "so she won't need drugs." It appears that she is aware that the presence of a trusted and well-prepared supporter will help her reach that goal. Help her recognize that a supporter is one ingredient for a successful experience. You (and she) know that most normal, motivated, informed women can achieve this goal and have a satisfying, even exhilarating, birth experience. But you cannot assure her a normal birth, can you? You cannot guarantee that she will not become exhausted! You do not know her individual pain threshold or her past associations with birth or pain. Ask yourself these questions: Have you done everything you reasonably can to inform her of the availability, the advantages, and the limitations of her options? Have you done your best to give her support, encouragement, and comfort? Have you encouraged her to take her labor as it comes, to listen to her body, and to be flexible? Do you also take her labor as it comes, listen to her, and are you flexible? If your answers are "Yes", you and she both can feel satisfied with this birth experience. If your answers are "Yes", you should not feel uncomfortable about her request for "drugs." If your answers are "Yes", you have met your legal and ethical responsibilities.

Note: “Ask a Lawyer" answers are not official Lamaze International positions and are not intended to substitute for consulting with your own attorney. Nayna Philipsen welcomes your questions. Please send them to "Ask a Lawyer," Lamaze International, 1200 19th Street NW, Suite 300, Washington, DC 20036-2422 or via E-mail to naynamon@aol.com.

As an LCCE, one of your goals is to help an expectant mother recognize in advance that each birth is unique. 


\section{Kay's Perinatal Krossword Puzzle JPE 9, 1}

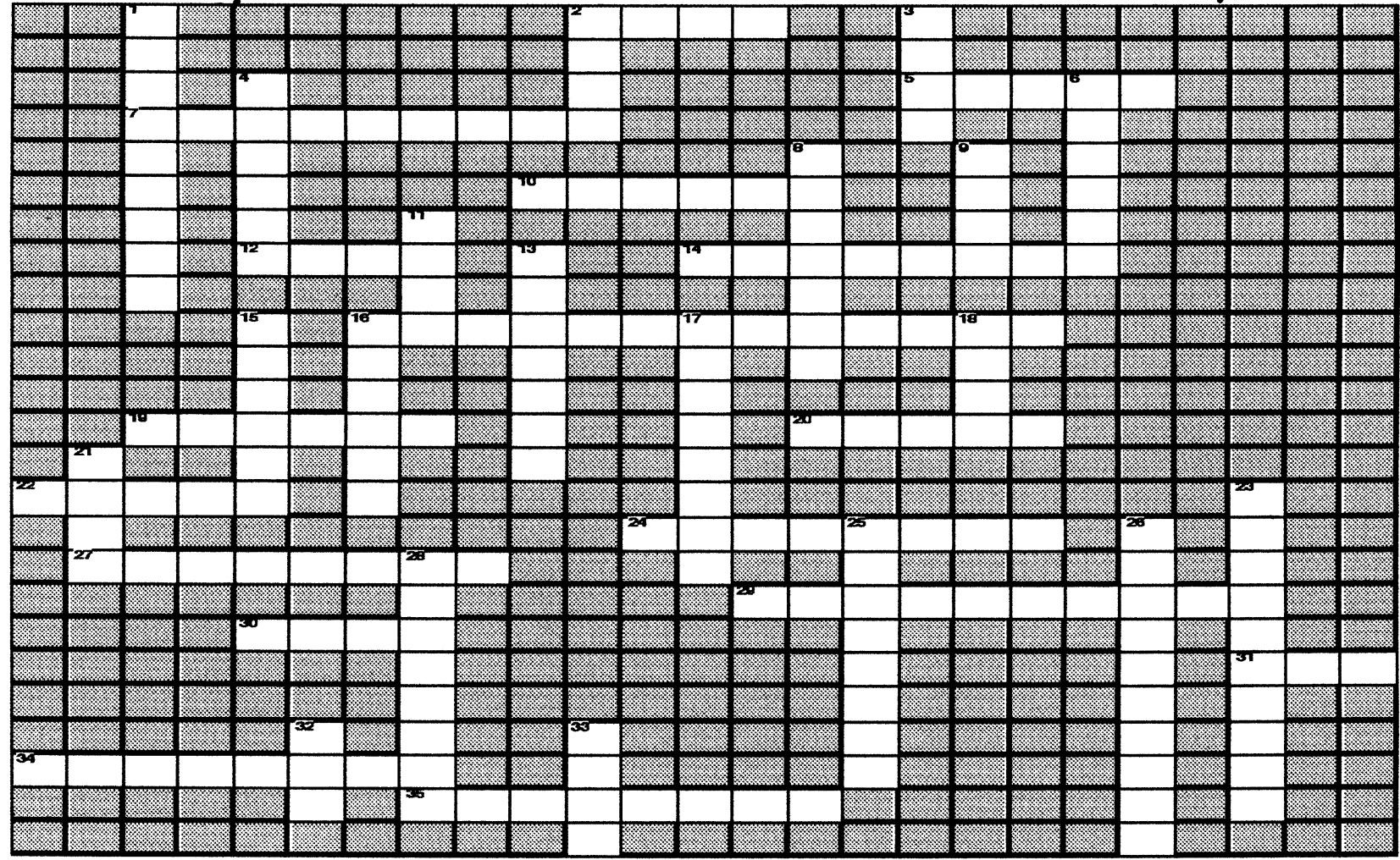

\section{ACROSS}

2 Water exercise class reduces symptoms of _ pain during late pregnancy. (Hammer)

5 The greatest threat of fetal defects caused by high temperature occurs during the _trimester.(Hammer)

7 In 1985 ACOG produced its first guidelines for exercise during _...(Hammer)

10 Marjorie wrote" Thank You, Dr. Lamaze". (Zwelling)

12 True family intimacy is a process that grows with _. (Polomeno)

14 Martin \& Starling believe educators must increase their familiarity with issues and recent changes in health services. (Polomeno)

16 Vari discusses interventions incorporating PMPS for improving outcomes(Vari)

19 PPM stands for Psychoprophylactic (Zwelling)

20 Marjorie Karmel learned PPM from Dr. Lamaze and Madame __ in Paris. (Zwelling)

22 Ideally, sedentary women should start exercising at least 6 _ prior to planned conception.(Hammer)

24 One aspect of the perinatal educator's role is to validate the couple's conflicting (Polomeno)

27 Cardiovascular fitness, __ strength, and endurance are maintained or improved in women who exercise while pregnant.(Hammer)

29 Cutrona says we are not born knowing how to be __ marital partners.(Polomeno) 30 Street defines intimacy as interactions that relate to open -disclosure and close personal exchanges.(Polomeno)

31 The transition to parenthood can be considered complete when the child is years old.(Polomeno)

34 This review will provide the childbirth educator with suggestions for developing individual programs.(Hammer)

35 PMPS can improve the of exclusive breastfeeding.(Vari) DOWN

1 Current breastfeeding support systems should be evaluated in WIC clinics, health clinics, and . (Vari)

2 PMPS intervention has similarities to UNICEF_ Friendly Initiative.(Vari)

3 Breast support during exercise is achieved by compression rather than and separation.(Hammer)

4 To monitor risk of dehydration, body should be checked occasionally before and after activity.(Hammer)

6 Conjugal intimacy includes -but is more than-_ intimacy. (Polomeno)

8 TPB stands for Theory of

Behavior.(Vari)

9 Zwelling interviews Elisabeth __ in this article.(Zwelling)

11 PMPS stands for Professionally Mediated __ Support.(Vari)

13 _ women who were already active prior to becoming pregnant do not need to change their activity .(Hammer)

15 Only $18 \%$ of new mothers continue breastfeeding for six _...(Vari) 16 A woman should not eat within an hour exercising to avoid an insulin reaction.(Hammer)

17 Healthy __are the desired outcome of perinatal education practice, the greate society, and ultimately the health care system.(Polomeno)

18 Polomeno lists phases of transitions to parenthood.(Polomeno)

21 Today Bing's greatest frustration is physician colleagues and herself not working as a _. . (Zwelling)

23 Early challenges for Bing were doctors and nurses who felt by knowledgeable parents. (Zwelling)

25 Pregnant women have heatdissipating ability, which is enhanced further with exercise conditioning.(Hammer)

26 Bing wrote "Six Practical Lessons for an Easier __.". (Zwelling)

28 The education component may be enhanced within a peer group where breastfeeding behavior is _...(Vari)

32 Vari compared breastfeeding outcomes at weeks postpartum.(Vari)

33 Bing had been teaching the _ method for almost 10 years when she decided to switch to PPM. (Zwelling)

By Kay Raheja, RN, FACCE

(See solution on page 53.) 